\title{
SONHOS E REFLEXOS: os traços de uma comunidade imaginada
}

\author{
Juan Camilo Buitrago Trujillo \\ Universidade de São Paulo \\ juan.camilo@usp.br \\ Marcos da Costa Braga \\ Universidade de São Paulo \\ bragamcb@usp.br
}

\begin{abstract}
Resumo: A Asociación Latinoamericana de Diseño Industrial (ALADI), foi fundada em 1980. A sua fundação foi o produto dos descontentamentos que um grupo de latino-americanos tinha com os processos de desenvolvimento social, econômico e cultural da região e foi construída em cima de um discurso latino americanista que era norteado por uma busca de identidade. Isto é visível nos discursos, principalmente atas, palestras e artigos de opinião e é alentado pela memória que atualmente tem vários dos atores. $O$ artigo pretende mostrar como as Identidades Visuais ${ }^{1}$ dos congressos da ALADI de 1980 e de 1984 expressaram essas ideias sobre a autonomia cultural da América Latina. Dada a sua natureza, no caso de Bogotá 1980 as análises formais estão embasadas nos princípios da Gestalt a partir do trabalho de Gomes (2004). A Identidade Visual do Rio 1984 foi estudada a partir das propostas de analise tipográfico de Silva \& Farias $(2004,2005)$. As entrevistas tiveram como base os métodos da história Oral, vistos em Alberti (2005). Procuramos detectar os sentidos criadores das peças, compreendendo nelas o principio de reflexo das convicções e das crenças dos atores, como defendem Lubar \& Kingery (1996) e Gombrich (2007). O cenário geral foi construído a partir da historiografia de Cancelli $(2003)$ e Hobsbawm $(2010,2011)$ e foi problematizado a partir dos eixos conceituais das comunidades imaginadas de Anderson (1993).

Palavras-chave: História do design, Design na América Latina, Identidade Visual, ALADI.
\end{abstract}

Abstract: The Asociación Latinoamericana de Diseño Industrial (ALADI) was founded in 1980 . Its foundation was the product of discontent that a group of Latin Americans had with the processes of social, economic and cultural development of the region and was built upon a Latin Americanist discourse, guided by a search for identity. This is visible in the discourses,

\footnotetext{
${ }^{1}$ Usamos o conceito de Identidade Visual com base na definição da Associação dos Designers Gráficos do Brasil: “...Conjunto sistematizado de elementos gráficos que identificam visualmente uma empresa, uma instituição, um produto ou um evento, personalizando-os, tais como logotipo, um símbolo gráfico, uma tipografia, um conjunto de cores..." (ADG, 1998, p. 59).
} 
especially acts, lectures and opinion writings and is encouraged by the memory that currently has several of the actors. The article aims to show how the Visual Identities of Congress ALADI 1980 and 1984 expressed the ideas on the cultural autonomy of Latin America. Bogota 1980's casso formal analyzes are based in Gestalt principles from the work of Gomes (2004). The Visual Identity of Rio 1984 was studied from the analysis of proposals for typographical Silva \& Farias (2004, 2005). The interviews methodological guide was Alberti (2005). All this looking for the senses detect creators of parts comprising them the principle of reflection of the beliefs of the actors, as suggested by Lubar \& Kingery (1996) and Gombrich (2007). The overall scenario was constructed from the historiography of Cancelli (2003) and Hobsbawm $(2010,2011)$ all this, trying to be questioned from the conceptual axes of imagined communities of Anderson (1993).

Keywords: Design history, Design in Latin America, Visual Identity, ALADI.

\section{Introdução}

O presente artigo é resultado de parte das pesquisas realizadas para tese de doutorado em andamento que pretende resgatar a história da Asociación Latinoamericana de Diseño Industrial (ALADI), criada em 1980. Tem como objetivo demonstrar como as Identidades Visuais dos congressos de 1980 e 1984 expressaram o discurso sobre a autonomia cultural da América Latina que tinha a Associação como eixo norteador naqueles anos ${ }^{2}$.

Em novembro de 1980 foi realizado em Bogotá o primeiro congresso da ALADI, segundo acordaram os latino-americanos presentes no Congresso do International Council of Societies of Industrial Design (ICSID) no México, em 1979.

ALADI tinha uma perspectiva precisa sobre a promoção dos ideais do Design Industrial como veículo para a conquista do desenvolvimento econômico, social e cultural da região, e como solução das necessidades fundamentais dos 'nossos povos'. O discurso inicial era contundente, baseado na ideia de que os países de América Latina são uma unidade cultural com um território e uma história comum, assim como uma língua que compartilha a mesma raiz em contraste com a desigualdade dos processos de modernização em cada um dos países membro.

Conforme acertado nas reuniões anteriores à fundação, a Associação seria chamada ALADI e, segundo a memória de alguns atores, sua Identidade Visual mudaria a cada edição de seu congresso previsto para ocorrer de dois em dois anos.

\section{ALADI 1980: O desenho do território.}

O símbolo do primeiro congresso foi formado pelo trajeto de uma linha que avança enquanto configura a região latino-americana. O projeto é de Jesús Gámez, arquiteto colombiano que foi o primeiro tesoureiro da ALADI. No processo de levantamento de acervos, ainda não foi possível conseguir as peças originais desta Identidade Visual. Entretanto, a versão oficial é visível em uma fotografia do evento fundacional, em algumas publicidades onde aparece como "marca" da Associação e

\footnotetext{
${ }^{2}$ Consideradas estas Identidades Visuais, pela coerência que cada uma manifesta ao frente das ideias sobre identidade (território e língua), assim como pela complementariedade que significa uma em função da outra.
} 
em timbres da papelaria na qual foram redigidas as atas de fundação. A sua reconstrução digital foi possível por meio da aplicação em uma capa da Revista Modulo do ano 1981 na qual está em bom estado. Contudo não é possível afirmar que o amarelo fosse a cor original na sua apresentação oficial de 1980 (figura 1). A qualidade das demais fontes visuais encontradas só permite fazer afirmações sobre proporcionalidades e algumas generalidades formais relativas ao logotipo, que parece estar presente ao lado do símbolo na abertura do evento de 1980.
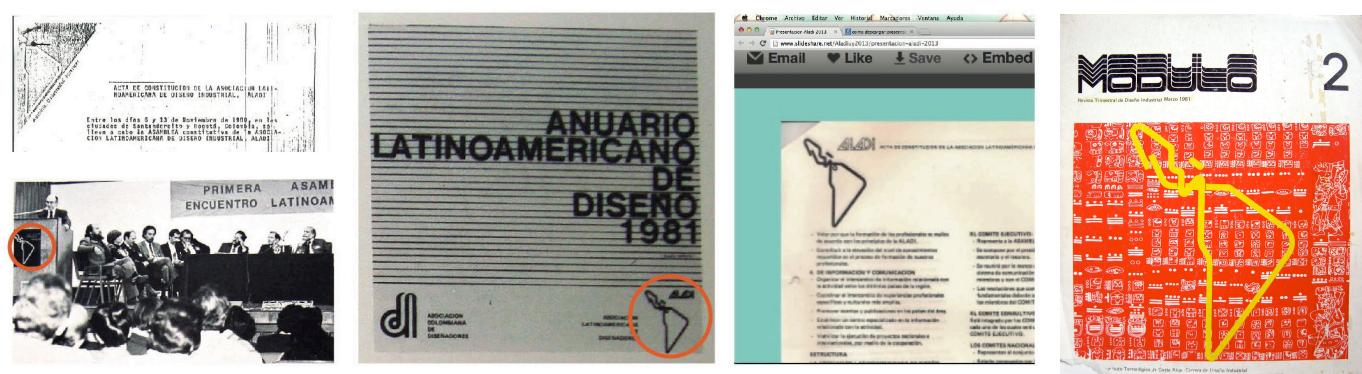

Figura 1 - Cópia da primeira folha da Ata de Constituição; Primeira assembléia; Anuário 1981; Versão da Ata no Slideshire e Revista Módulo no 2 de março de 1981.

Esta linha que continua com igual espessura no seu trajeto, está conformada por 3 tipos de arcos e 3 tipos de linha retas: diagonais (+/- 30 e 60), horizontais e verticais. Caracteriza-se por um jogo com vários princípios geométricos: o traço do mapa está mais ou menos inscrito em um triângulo girado quase 60 을 contra o sentido do relógio (figura 2), que poderia ser completado na leitura dos pontos mais extremos segundo a lei de fechamento da Gestalt (linha I-J na figura 2$)^{3}$.

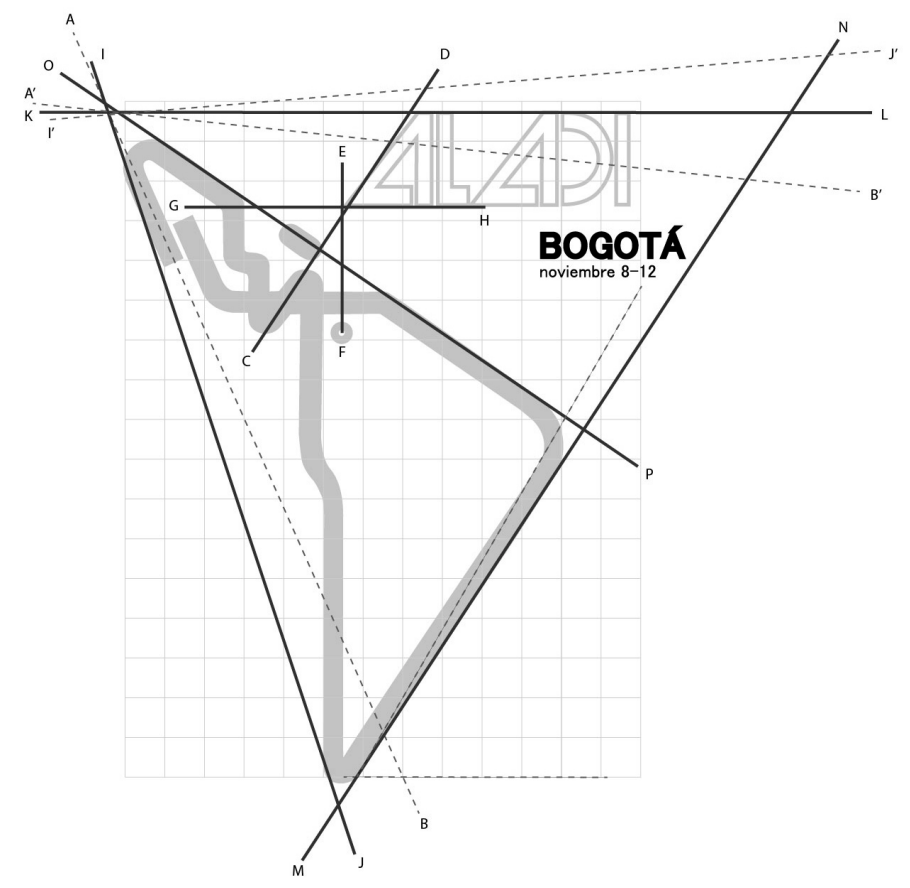

Figura 2 - Relações geométricas do símbolo de 1980. Elaborado pelo autor, com base na pesquisa realizada.

\footnotetext{
${ }^{3}$ Poderia, pois é notório na linha tracejada A-B na figura 2, não consegue fechar no vértice inferior do traço. Os princípios da Gestalt usados são expostos por Gomes (2004).
} 
$\mathrm{Na}$ construção dos fillets foram usados cinco diâmetros, utilizando uma proporção em média de 1:1,53 entre eles.

Sobre o logotipo não há evidencias de que Gámez tenha projetado o alfabeto completo da tipografia, só a palavra ALADI. O ponto que dá inicio ao caráter " $A$ " parecesse estar situado 2,5 unidades em cima da linha superior do traço do mapa em um ponto no qual cruzam-se três linhas: o círculo que representa Bogotá (linha E-F, figura 2), a projeção da diagonal C-D (paralela à linha $M-N$ ) e a linha G-H que parece ser o ponto no qual a vertical que sobe, muda de sentido girando 60 graus para começar a dar forma ao México.

O principio de fechamento da Gestalt também é observável nas letras " $A$ " e " $D$ " do logotipo. Uma olhada em sua forma nos remete ao estilo tipográfico geométrico enfatizado por Herb Lubalin em sua fonte AvantGarde de 1970. Embora por causa da referida qualidade do acervo não se possa fazer uma análise mais detalhada, na simples comparação visual pode-se ver a proximidade estilística entre as duas tipografias (figura 3). Observa-se que há semehanças na geometria usada nos dois logotipos, como o tipo de triângulo insinuado visualmente na letra " $A$ " de ambos e em soluções de 'kerning' (ajuste dos espaços entre os caracteres).

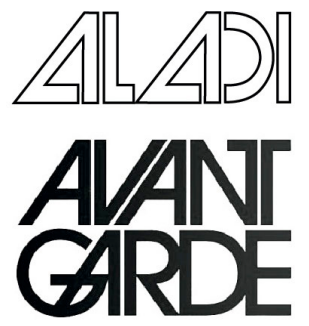

Figura 3 - Logotipos da ALADI e Avant Garde. Elaborado pelo autor, com base na pesquisa realizada.

Ainda que o símbolo e as aparentes decisões tipográficas não apliquem rigorosamente os mesmos princípios geométricos mencionados ${ }^{4}$, é razoável afirmar que existiu uma pretensão por usá-los. Na peça é mais ou menos possível detectar tendências no uso das formas limpas, puras, sem élan, senso de velocidade ou urgência, como Stolarski (2006, p. 219) caracteriza o concretismo no design gráfico. Se dermos uma olhadinha no capital social e cultural de Gámez, pode-se intuir a sua relativa afinidade com o sistema visual que para uma geração significou os princípios da ordem e a comunicação efetiva, como afirma Meggs (2009) quando fala do Estilo Tipográfico Internacional.

Jesús Gámez é colombiano. Estudou arquitetura na Universidad Nacional na sede de Medellín obtendo o título em 1965. Década politica e socialmente ativa naquela universidade. Depois estudou Design Industrial na HfG de Ulm em sua fase final $^{5}$ assim como Estética na Universidade de Stuttgart em 1968.

${ }^{4}$ Entre outras, a inclinação é menor do que 60으, o fechamento do triângulo e inexato, não existe simetria instrumental (o reflexo do triângulo J-I, O-P, M-P deveria ser aquele conformado por O-P, P-N e I'-J' na figura 2). Na tipografia parece haver larguras diferentes nas hastes da "I", a "L" e a "A.

${ }^{5}$ A HfG de Ulm fechou em 1968 porém, no currículo do Gámez no acervo da Universidad Nacional, está registrado que ele estudou lá entre outubro de 1967 e junho de 1969. Considerando essas datas, entendemos que seu currículo pode ter sido preenchido equivocadamente em 1976 (AlUNAL, Sem classificação). 
$\mathrm{Na}$ ideia de construir uma zona visível, demarcada, soberana, na qual seus próprios habitantes pudessem configurar sua própria realidade, a representação do território parece ter sido uma boa ideia para a primeira Identidade Visual da ALADI. Afinal, se Anderson (1993) tem razão, um dos princípios fundamentais para estabelecer a identidade nacional é a identificação de um território. O desenho da América Latina para o congresso fundacional da Associação virou um símbolo altamente significativo para seus atores. Era a representação de um território que se fechava mostrando aos 'outros' a sua existência "...Aquí está... esto, una bandera [...] una línea que define el territorio [...] la tierra latinoamericana [...] es luchar por una identidad...". Declaração de Ivens Fontoura enquanto descrevia o símbolo nas suas mãos (FONTOURA, 2013) ${ }^{6}$.

\section{ALADI 1984. Uma língua para nossa terra.}

Ao congresso de 1980 seguiu-se o Congresso de Havana em 1982, do qual ainda não conseguimos fontes documentais ${ }^{7}$. Em novembro de 1984 ocorreu o 3 ㅇ Congresso de ALADI no Rio de Janeiro, que propôs seis temas para discutir os eixos da Associação acompanhados por noções como "território", "natureza", "população", "cultura" e "nação", estreitamente ligadas com o sentido da "terra" e usadas nas diversas peças gráficas do evento (figura 4). O responsável da Identidade Visual foi Joaquim Redig, membro fundador da ALADI.

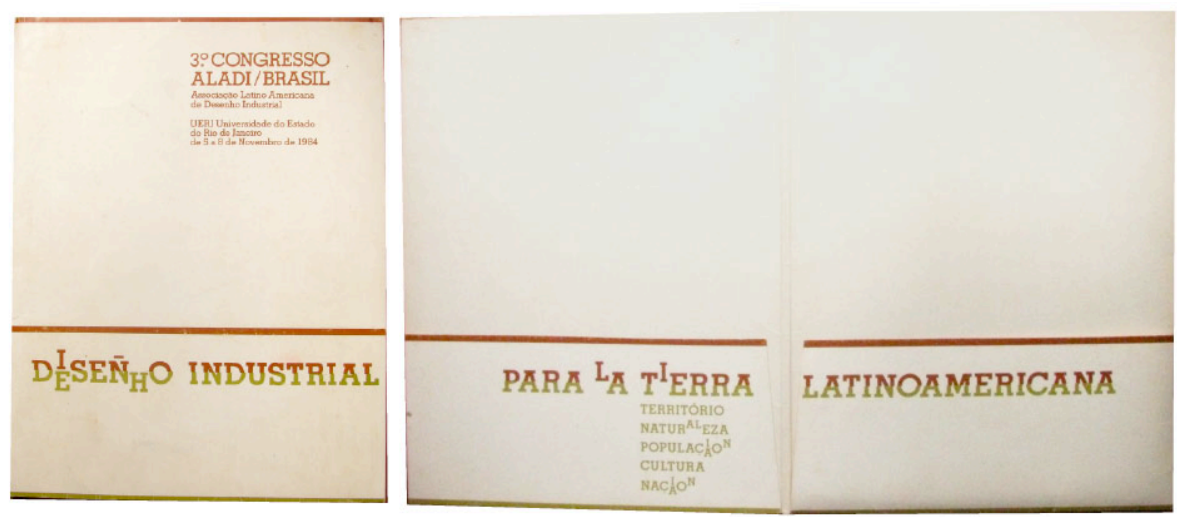

Figura 4 - Capa e corpo interno da pasta. Acervo de Marcos Braga

Duas grandes razões nortearam o projeto visual. A primeira, a experiência que tiveram Valéria London e Joaquim Redig na Colômbia em 1980. Segundo Valeria, quando eles chegaram a Bogotá tinham preparada uma apresentação sobre as diferentes concepções do design, resultantes das discussões que recentemente tinham-se dado no interior das associações brasileiras. Redig lembra que achou que se

\footnotetext{
${ }^{6}$ A pesar da diferencia de estilo, podemos ver ideia similar expressada com o mapa da América do Sul na obra "América Invertida" do uruguaio Joaquín Torres García em 1943. Nela por meio do desenho do território continental o artista simboliza e defende a busca por caminhos próprios e por uma identidade latino americana (SCHWARTZ, 2013).

${ }^{7}$ Não se ignora a importância que a identidade visual do Congresso de Cuba de 1982 pode ter tido na construção de uma representação das idéias da ALADI. Porém, até o momento não foi possível nenhum contato com os responsáveis por este evento e nem foi identificado nos documentos levantados qualquer imagem dessa identidade. Entretanto, as identidades de 1980 e 1984 são muito representativas e se complementam na própria narrativa dos entrevistados.
} 
falasse devagar, as limitações da língua não interfeririam. Mas, depois que terminou a sua apresentação percebeu que ninguém the compreendeu. Pensou: 'se supero a barreira da língua, consigo uma integração mais certa'.

Mais uma razão daria elementos para a exploração com a tipografia: na busca da unidade era importante assinalar as coisas que eram comuns entre os países ${ }^{8}$. Lembrando o propósito pela integração, Redig percebeu que tanto o espanhol quanto o português tinham similaridades que era necessário explorar e demonstrar: "...a língua é quase a mesma [...] escrito é muito parecido [...] a integração das línguas..." (REDIG, 2013b) ${ }^{9}$.

A Identidade Visual de 1984 pode ser classificada como uma tipografia composta por caracteres "maiores" de duas cores e outros "menores" de uma cor só. As primeiras representam as letras que não mudam na escrita de uma palavra determinada. As menores são aquelas nas que se marca a diferença entre as línguas.

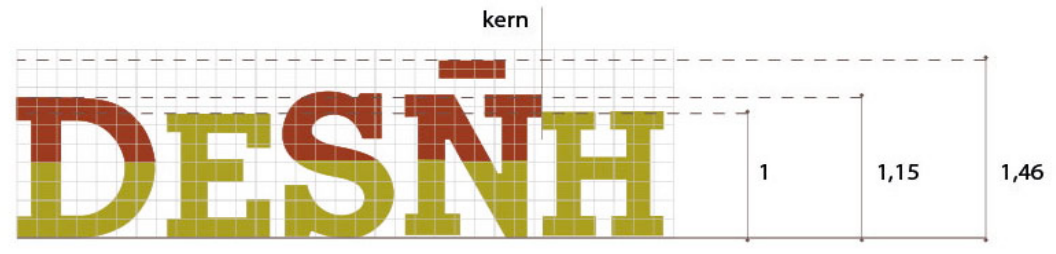

Figura 5 - Os caracteres maiores, de duas cores, são 1,15 (+/-) vezes maiores do que
os menores, de uma cor. Elaborado pelo autor, com base na pesquisa realizada.

Uma rápida passada pelos sistemas classificatórios para as tipografias apresentados por Silva \& Farias (2005), sinala que esta tipografia pode ser considerada desprendida da linha chamada "egipcianas" no sistema Thibaudeau; Mecânicas no Vox; Egipciana no DIN 16518 e Geométrica no sistema de Giò Fuga. Decerto, as diferentes partes do traço das letras confirmam a tendência retilínea do projeto de Redig nas serifas, hastes, barras e braços: estas partes são retângulos ou paralelogramos isométricos mais ou menos homogêneos. Na figura 6 é possível ver que tanto as barras $(A, H, T)$ quanto o braço da letra " $L$ " tem igual espessura (aqui 1 ). Também é visível que a haste do " $T$ ", que poderia representar todas aquelas letras maiores do sistema, mede 1,5 unidades de largura e que o haste da " $\mathrm{H}$ " representando os caracteres menores- tem largura de 1 aproximadamente ${ }^{10}$.

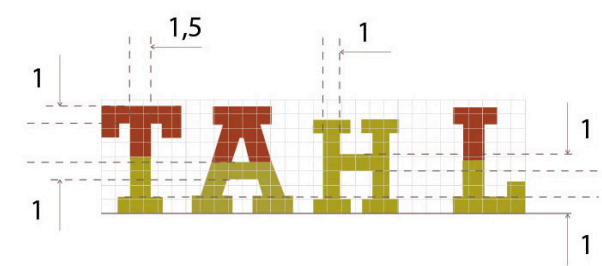

${ }^{8} \mathrm{O}$ mito da América Latina do pesadelo e a utopia é velha. As ideias de uma região similar provem da identificação sobre a miséria e a pobreza, assim como da fraternidade e a solidariedade de muitos intelectuais latino-americanos desde o século XIX. Daí que para diferentes poetas, políticos, artistas e arquitetos da região fosse importante encontrar as suas similaridades (Cancelli, 2003).

${ }^{9}$ Xul Solar (Argentina 1887-1963) tinha explorado a confraternização visual entre as duas línguas no seu sistema chamado 'neocriollo'.

${ }^{10}$ A Identidade Visual apresentou diferenças entre o projetado e o impresso dados problemas técnicos na época. O próprio Redig assinalou um erro na impressão final da pasta no seu depoimento. 


\section{Figura 6 - Espessuras das letras. Elaborado pelo autor, com base na pesquisa realizada}

Dentro da tendência geométrica é possível ver o uso sistemático de três círculos para a construção dos bojos de algumas letras. A figura 7 mostra como as letras " $D$ " e " $O$ " parecem terem sido construídas a partir de uma circunferência que seria também a que é insinuada no " $C$ ". Já os bojos da letra " $P$ " $\mathrm{e}$ " $U$ " coincidem com o uso de um circulo que resulta da metade dos bojos anteriores. A letra " $R$ " tem um bojo feito por um arco com 1,8 unidades que é a mesma dimensão do arco que dá forma ao início da sua perna.

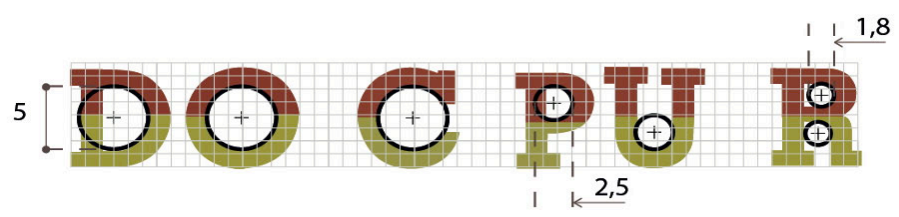

Figura 7 - Circunferências aplicadas no alfabeto. Elaborado pelo autor, com base na pesquisa realizada

É possível determinar três divisões gerais no grid do logotipo principal, proporção que é igual nos outros textos. A primeira é a linha $A^{\prime}-B^{\prime}$ a segunda a $C-D$ e a terça sendo $E^{\prime}-F^{\prime}$ (figura 8). Entre elas existem 7 unidades de distancia, o que pode expor a simetria com que foi concebida a peça. Assim é possível perceber um ritmo homogêneo no jogo tipográfico: a distancia entre as linhas $A$ e $A^{\prime}$ é a mesma existente entre as linhas $A$ e $C, C$ e $E$ e finalmente $E$ e $E^{\prime}$. Isto explica-se porque a linha de base dos caracteres maiores (linha A-B) marca o alinhamento inferior do braço da letra " $E$ " $e$ a barra da letra " $\mathrm{H}$ "; a linha media da grid (C-D) é a linha que divide na metade as letras bicolor, entretanto é também a linha superior dos caracteres menores. Assim como a linha média das letras menores que estão na parte superior da malha (linha EF) é a linha superior das letras maiores.

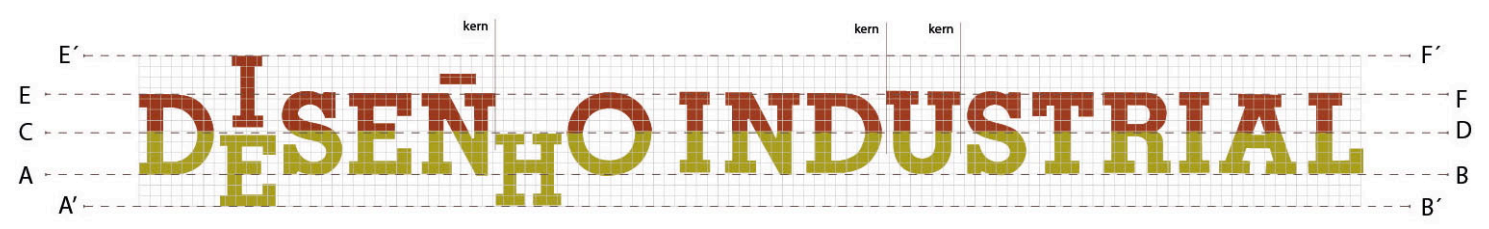

Figura 8 - ‘Grid’ do logotipo principal. Elaborado pelo autor, com base na pesquisa realizada.

O uso das maiúsculas responde aos princípios formais para o jogo pretendido com a tipografia. Segundo o próprio Redig, se fosse usado caracteres em caixa baixas, teria ocorrido alguns problemas nas linhas de construção (REDIG, 2013b).

Com estas anotações não afirmamos que ele fez um trabalho estritamente construtivo no processo. Indagado sobre o aparente grid que governa a diagramação na capa da pasta do Congresso (figura 4), ele respondeu que se existe alguma régua na proporção, ela saiu na espontaneidade. Contudo, como em Gámez, no trabalho de Redig pode-se ver a sua proximidade com os princípios do Estilo Internacional suíço 
afinados com o concretismo. Uma olhada ao seu trabalho pode reafirma-lo ${ }^{11}$.

Redig nasceu no Rio de Janeiro na década de 1940. Seu pai foi arquiteto. Sua mãe, filha de jornalista, dedicava-se as tarefas da casa e, segundo lembra Redig (2013a), tinha uma intensa participação escrita em alguns jornais da cidade, assim como uma ativa participação com as coisas da igreja, principalmente, com o trabalho de Dom Hélder Câmara.

A sua sensibilidade no uso da criatividade por causa do trabalho do seu pai (arquiteto); a reconhecida influencia da sua mãe na reflexão; o seu contato com o modernismo na obra de Lúcio Costa; a escola na qual fez faculdade, onde teve a oportunidade de formar a estreita relação com Aloisio Magalhães, entre outras coisas, fizeram de Redig um brasileiro sensível com o desenvolvimento equitativo, que entendeu a sua profissão como um caminho para fazê-lo realidade: talvez isso explique o seu ativo trabalho nos corpos associativos do país. E talvez, possa explicar também porque foram Ihe sensibilizando aqueles caminhos latino- americanistas:

"...t(i)erra como nosso contexto de vida, como nossa realidade, t(i)erra como nosso território, nossa natur(al)eza, nossa popula(ción)ção, nossa cultura, enfim, nossa na(ción)ção. T(i)erra como nossa fertilidade natural e cultural, t(i)erra como nossa história de sofrimento, exploração, e miséria, t(i)erra como nossa efusiva energia humana. Assim, diferenciadas mas integradas, como quisemos mostrar inclusive através da imagem visual de nosso encontro no Brasil..." (REDIG, 1984, p. 3).

\section{Antropofagia modernista na América Latina do pesadelo.}

As ideias sobre a autonomia tecnológica eram para ALADI, as ideias da autonomia cultural. Nessa fórmula, eles introduziam o Design Industrial quase homologando-lo com a técnica. A técnica, então, como a forma da cultura. De onde vem essa ideia? Rapidamente se poderia pensar em dois fontes: com as suas variações, os paradigmas da arquitetura moderna dos primeiros 15 anos do século $\mathrm{XX}$, do qual bebeu a Bauhaus e toda a linha alemã. Por outro lado as apostas conceituais da plástica construtiva que eram principalmente levantadas ao mesmo tempo na Holanda e na URSS e que também termina sendo depositada na Bauhaus por causa dos famosos debates iconoclásticos dos soviéticos e dos conflitos pessoais entre Van Doesburg e Mondrian no caso holandês.

Esse ethos muito próximo do ascetismo européio-saixão acabou se materializando em uma linguagem formal 'neutra', que buscava uma pretendida 'objetividade' que negasse a presença do autor para privilegiar o sentido da criação: a satisfação das necessidades dos outros no sentido geral e da "comunicação efetiva" no particular. Nas mudanças do passo das décadas, no processo de especialização do Design Gráfico, era esperado que fossem privilegiados os princípios da comunicação visual e que o fossem por meio do uso de um sistema formal 'limpo e puro'. Tanto os caminhos transitados pelos arquitetos modernos com a linguagem modernista, como 0 caminho da critica à arte burguesa pelas vanguardas, assim como as suas respectivas variações, hibridações, criações e atualizações, explicam a proximidade que Gaméz e Redig tinham com a linguagem.

Por outro lado, no contexto dos debates soviéticos dos primeiros anos da década dos anos 1920, Lucena aprofunda mais um pouco as relações entre

\footnotetext{
${ }^{11}$ Por exemplo a Identidade Visual projetada para Nova América, Queiroz Galvão, Empetur ou Furnas. Sugerimos ver http://designredig.com/contato/projeto-grafico/
} 
criatividade, inovação e invenção "...como valores supremos inevitáveis..." (2012, p. 22), como mecanismo para conseguir a transformação e a reconstrução da vida social de acordo com os novos tempos. De mudar o mundo como afirma Hobsbawm (2011), contra quem que querem negar a oportunidade da URSS de configurar a sua própria realidade? Com as devidas proporções, o espírito que transitava na Europa na segunda metade do século XIX, parecia estar transitando na América Latina a partir das revoluções da primeira década do XX (movimento estudantil em Córdoba, Revolução mexicana, indigianismo peruano, brasilianidade, entre outros):

“...el interés por estos problemas históricos se reavivó de forma espectacular en la década de 1970. En sus Orígenes refleja los debates políticos específicos de la izquierda en aquella zona del mundo [o terceiro mundo], y en particular en Latinoamérica de las décadas de 1950 y 1960 [...] El enemigo internacional era obviamente el "imperialismo" (sic), identificado ante todo con EE.UU [...] para los comunistas ortodoxos significaba la creación de un frente nacional común contra el imperialismo de EE.UU y la "oligarquia" (sic) local..." (HOBSBAWM, 2011, p. 360).

Gámez e Redig estavam comprometidos com o estilo gráfico da escola suíça. No caso do Gámez dada a sua formação como arquiteto na Universidad Nacional na Colômbia, Designer Industrial na Escola de Ulm e Estética na Universidad de Stuttgart. Por seu lado, Redig estando inserido em uma escola que nos seus primeiros anos implementou com rigor o modelo pedagógico da mesma HfG de Ulm dentro do qual estava inserida a linguagem gráfica da escola européia, assim como com a estreita proximidade com Aloisio Magalhães e com outros de seus mestres. Isso explica as generalidades do 'estilo' no qual se poderiam caracterizar as duas peças feitas para ALADI. Mas o uso da linguagem não era nem para Gámez e nem para Redig uma inocente maneira de se atualizar frente às suas influências. Tanto o arquiteto moderno (Gámez), quanto o designer (Redig) entendiam na linguagem gráfica dita 'neutra', uma forma de conquistar a comunicação enquanto eram usados códigos formais que representavam o porvir: sem decoração; perto das paredes brancas dos sonhos de Loos; na linha social da criação humana.

Mas o sentido da objetividade extrema na obra gráfica que era pregoada por parte dos construtivistas mais rigorosos, não parece se cumprir nestes dois casos. As diferentes 'imperfeições' mostradas no projeto da Colômbia, quanto no trabalho do Brasil, junto com a confissão de Redig sobre a espontaneidade em varias decisões de design, deixam ver uma diferença importante na maneira de trabalhar dentro do sistema concreto destes dois latino-americanos em frente dos concretistas europeus ou norte-americanos. Enquanto Aicher desenhou o grid do logotipo da Braun antes da forma das letras, ou Bonsiepe proponha um estrito modelo para o redesign de um catálogo a partir da extrema síntese e a negação do criador a partir da formula de Shannon (BONSIEPE, 1968), fica claro na análise feita das peças da ALADI que tanto Gámez, quanto Redig tomaram varias decisões em função da sua intuição. Não afirmamos que seja um jeito consciente na sua metodologia de trabalho, na verdade não sabemos. Digamos que, valorizando os princípios da eficácia perceptiva, o pragmatismo visual e a sistematização, princípios sublinhados por Stolarski (2006) sobre o propósito ulmiano, ordenados desde o sistema internacional criado na Suíça e herdeiros do imbricado caminho construtivista desde a segunda década do século XX, Redig e Gamez deram forma às necessidades comunicativas que tinham a frente, mas também (e igualmente) às suas expressões como autores. 
"...la esencia de la Antropofagia modernista, a saber, la de deglutir, comer, asimilar los paradigmas extranjeros y vomitarlos de otra forma [...] a través de la enorme y admirable capacidad de autorenovación de los latinoamericanos [...] deglutida positivamente, $y$, por eso, seríamos "la Utopía realizada, bien o mal frente al utilitarismo mercenario y mecánico del Norte" (sic)..." (CANCELLI, 2003, p. 66).

\section{Território e língua: o desenho de uma comunidade imaginada.}

Gámez e Redig projetaram duas Identidades Visuais nas quais é visível um discurso formal tão reivindicatório como os seus escritos. Assim como não é inocente o uso da linguagem gráfica, também não é gratuito que Gámez tenha traçado um mapa da América Latina demarcando o território de uma comunidade que compartilha os mesmos problemas. Afinal, é no território que se estabelece um dos principais elementos da identidade nacional (ANDERSON, 1993). Não afirmamos que tal consciência existisse no propósito de Gámez, na verdade não o sabemos. Contudo, como um reflexo das conviç̧ões e crenças, das expectativas, como assinala Gombrich $(2007)^{12}$, isso pode explicar o sentido que vários dos integrantes da ALADI tinham e ainda tem sobre essa imagem.

Como no projeto de Gámez com o território, não achamos fortuito o jogo com a língua no caso de Redig. As cores utilizadas estão alinhadas com o sentido da terra, não só como uma porção limitada já demarcada por Gámez, e sim como o substrato no qual é semeada uma semente... no qual se estabelecem as raízes "...verde e o marrom... a terra... a terra latino-americana; então eu tomei as cores da terra mais material, ainda aí a terra seja mais conceitual... a terra: território... a nossa terra como se diz..." (REDIG, 2013b).

Ao traço do mapa que mostrava que o território tinha-se demarcado, seguiu-se o estabelecimento de um idioma. Foi demarcada uma terra imaginada na qual é falada 'uma mesma língua': uma comunidade política imaginada como inerentemente limitada e soberana, como Anderson define o conceito de nação $(1993, \text { p. } 23)^{13}$.

Por outro lado, em geral, a amizade percebida entre os governos locais e USA não era bem vista pelos filhos da classe média que sonhavam com a autonomia cultural, o resgate das raízes e a procura "do nosso". Nos locais onde Gámez e Redig fizeram faculdade (Unal e ESDI), a crítica a tais processos estava viva e se acendia sobre as reflexões que entre outras correntes, oferecia o marxismo "...el principal enemigo era la burguesia que, lejos de tener intereses opuestos al imperialismo estadounidense, se identificaba básicamente con este último y funcionaba como agente local del capital monopolista norteamericano e internacional..." (HOBSBAWM, 2011, p. 361) $)^{14}$.

\footnotetext{
${ }^{12}$ Lubar e Kingery (1996) sublinham a "Cultura e universo mental" que tem muita similaridade com a ideia de Gombrich sobre a peça artística como produto das exigências sociais (2007). Uma ideia similar é exposta por Bucaille e Pessez (1989) no dilema marxista da infraestrutura e a superestrutura.

13 "...lo más importante de la lengua es, con mucho, su capacidad para generar comunidades imaginadas, forjando en efecto solidaridades particulares..." (ANDERSON, 1993, p. 189).

${ }^{14}$ Vamos somar-lhe este outro mote "...os brasileiros, independentes desde 1822, sentiam-se ainda ontem, e mesmo hoje, em uma situação "colonial", não com relação a Portugal, mas com relação à Europa e aos Estados Unidos. Hoje [1967] é comum o gracejo: "Não somos Estados Unidos do Brasil, mas o Brasil dos Estados Unidos"..." (BRAUDEL, 1998, p. 39).
} 
Seria plausível pensar em que a luta contra tal inimigo começava com as definições daquilo que fosse identificador... neste caso, no discurso verbal, as necessidades de "nossos povos"; no discurso gráfico, o território e a língua, e que a partir desses identificadores fosse possível a construção de uma comunidade imaginada soberana.

As ideias mais gerais, mais estruturais na construção da identidade, muitas vezes impostas, sugeridas ou configuradas a parir do discurso verbal, contribuem na construção de comunidades que não podem-se conhecer em toda a sua expansão, mais que são apropriadas pelos indivíduos membros, dada a sua capacidade de ser imaginadas. E são imaginadas, entre outras coisas, pela terra que compartilham como com a linguagem que falam. Os elementos são reforçados por um determinado 'material didático' no caso dos nacionalismos como os que são expostos por Anderson: hinos, costumes, e imagens como as bandeiras. No caso de ALADI, talvez dado o sentido das Identidades Visuais e da memória que ainda hoje é expressada pelos atores a partir delas: como imagens visuais que reforçam o discurso verbal dos latinoamericanos envolvidos no processo.

\section{Considerações finais: Um Território, Uma Língua - Uma Bandeira.}

À ideia colombiana do território foi somada a versão brasileira da língua. Com o propósito reivindicatório, que claramente era inspirado nos embasamentos conceituais da ALADI, presente nas motivações de Gámez e Redig, puderam ser recriados nas suas identidades visuais os princípios da semelhança como principio para conquistar a integração de uma Latino América que eles tinham desenhado nas suas imagens mentais. Elas ilustraram o discurso reivindicatório sobre a autonomia cultural da América Latina que tinha a Associação como eixo norteador. A partir da dupla conceitual 'território - língua', as Identidades Visuais podem ter demarcado uma terra sonhada na qual é falada 'uma mesma língua': uma comunidade política imaginada. Dai que, por exemplo, Ivens Fontoura, ex-presidente de ALADI, olhe naquelas peças a ideia de uma bandeira que simboliza a existência de um território e a sua soberania sobre a qual é construída a sua identidade

"...La necesidad de identidad que es una cuestión cultural [...] cada grupo social busca una identificación y [en este caso] ese grupo social se llama diseñadores de América Latina... había necesidad de contar para los demás que hay la identidad [...] una necesidad fundamental... una marca... una bandera..." (FONTOURA, 2013).

Bandeira que lembra que existe um território no qual se fala uma língua... o sonho de uns atores apaixonados com a idéia de mudança social. Para fazer apologia de Weber (2008), como as ações racionais que respondem aos fins e valores... o seu reflexo nos seus discursos e nas suas criações materiais.

\section{REFERÊNCIAS}

ABRAMOVITZ, J. Entrevista concedida à J. C. Buitrago. Rio de Janeiro, RJ, Brasil. 1h $29 m$ de duração. 4 de novembro de 2013.

ADG. ABC da ADG. São Paulo: Blucher, 1998.

ALBERTI, V. Manual de História Oral. Rio de Janeiro: FGV, 2005.

ANDERSON, B. Comunidades Imaginadas. Reflexiones sobre el origen y la difusión del nacionalismo. México D.F: Fondo de Cultura Económica, 1993.

BONSIEPE, G. A method of quantifying order in tipographic design. The Journal of 
Tipographyc Research , I/ (3), 1968. p. 203-220.

BRAUDEL, F. Civilização Material, Economia e Capitalismo. Séculos XV-XVIII. Vol. 3. O Tempo do Mundo. São Paulo: Martins Fontes, 1998.

BUCAILLE, R., \& PESEZ, J.-M. . Cultura Material. Em Enciclopedia Einaudi, Vol. $16 .$. Lisboa: IN-CM, 1989. p. 11-47

CANCELLI, E. América del deseo: pesadilla, exotismo y sueño. Estudios Sociológicos , XXI (1), 2003. p. 55-74.

FARIAS, P. Notas para uma normatização da nomenclatura tipográfica. Anais do P\&D Design (versão em CD-Rom sem numeração de pagina). São Paulo: FAAP, 2004.

FONTOURA, I. Entrevista concedida à J. C. Buitrago. São Paulo, SP, Brasil. $1 \mathrm{~h} 20 \mathrm{~m}$ de duração. 13 de Setembro de 2013.

GOMBRICH, E. La historia del arte. China: Phaidon Press Limited, 2007.

GOMES, J. Gestalt do Objeto. Sistema de Leitura Visual da Forma. São Paulo: Escrituras, 2004.

HOBSBAWM, E. Nacionalismo y Nacionalidad en América Latina. En P. Sandoval, Repensando la Subalternidad. Miradas Críticas desde / sobre América Latina. Lima: Envión Editores / Instituto de Estudios Peruanos (IEP), 2010. p. 311-326

HOBSBAWM, E. Cómo Cambiar el Mundo. Buenos Aires: Crítica, 2011.

LONDON, V. Entrevista concedida à J. C. Buitrago. Rio de Janeiro, RJ, Brasil. 2 h. 30 mins. de duração. 31 de outubro de 2013.

LUBAR, S., \& KINGERY, D. História a partir das coisas: tendências recentes nos estudos de cultura material. Anais do Museu Paulista, 4, 1996. p. 265-282.

LUCENA, D. Arte y revolución. Sobre los fotomontajes olvidados de Tomás Maldonado. Izquierdas (13), 2012. p. 18-28.

MEGGS, P. História do design gráfico. São Paulo: Cosac Naify, 2009.

PAMIO, O. Hacia un Diseño Independiente. Módulo (2), 1981. p. 1-2.

POLO, R., LÓPEZ BIELSA, F. J., BLANK, L., ROBLES, P., ORTÍZ, F., RIVERA, S., e outros. La Carreta del Diseño (3). Interdiseño '78. Documento de Intención. (R. Polo, J. Gámez, \& H. Lozano, Edits.) Valle de Bravo, México, 1980. p. 17-18.

REDIG, J. Desenho Industrial para a Terra Latinoamericana: Tema ou Lema? Discurso de bem-vindas do 3을 Congresso da ALADI. Rio de janeiro, 1984.

REDIG, J. Entrevista concedida à J. C. Buitrago. São Paulo, SP, Brasil. 1h de duração. 16 de outubro de 2013a.

REDIG, J. Entrevista concedida à J. C. Buitrago. Rio de Janeiro, RJ, Brasil. 1h 45m de duração. 1 de novembro de 2013b.

SCHWARTZ, J. Fervor das vanguardas. São Paulo: Companhia das Letras, 2013.

SILVA, F. L., \& FARIAS, P. Um panorama das classificações tipográficas. Revista Estudos em Design. 11 (2). Rio de janeiro: Estudos em Design, 2005. p. 67-81.

STOLARSKI, A. A identidade visual toma corpo. En MELO, C. H. O Design Gráfico Brasileiro Anos 60 . São Paulo: Cosac Naify, 2006. p.216-247

WEBER, M. Economía y Sociedad. Esbozo de Sociología Comprensiva. México: Fondo de Cultura Económica, 2008.

Agradecimentos.

FAPESP e Universidad del Valle em Cali, Colômbia. 